\title{
Espaços livres para a fantasia: Descrição de imagem, de Heiner Müller
}

[Free spaces for fantasy: Description of image, by Heiner Müller]

Luciano Gatti ${ }^{1}$

\begin{abstract}
The article discusses Heiner Müller's play Description of image as an example of his late playwriting. By analyzing the various movements of the text, we seek to understand its qualification, given by Müller himself in his autobiography, as an autodrama, a term that would refer, according to the hypothesis of the article, to a comparison with the Brechtian genre of the learning play (Lehrstück).
\end{abstract}

Key-words: Heiner Müller; german theater; learning play.

Resumo: O artigo aborda a peça Descrição de imagem, de Heiner Müller, como um exemplo de sua dramaturgia tardia. Pela análise dos diversos movimentos do texto, busca-se entender a qualificação, dada pelo próprio Müller em sua autobiografia, da peça como um autodrama, termo que remeteria, segundo a hipótese do artigo, a um confronto com o gênero brechtiano da peça de aprendizagem (Lehrstück).

Palavras-chave: Heiner Müller; teatro alemão; peça de aprendizagem.

Heiner Müller escreveu Descrição de imagem (1984) a partir do desenho de uma estudante de cenografia. A imagem havia sido esboçada como o retrato de um sonho, uma paisagem onírica composta por poucos elementos - nuvens e árvores ao fundo, uma casa no primeiro plano, uma mulher à mesa no jardim, um homem na soleira da porta, três pássaros. Ao descrever o desenho, Müller confere movimento à imagem, associando as figuras em cenas de violência, sexo e morte. A mulher aparece como uma visitante do reino dos mortos, o homem seu assassino. A imagem revela-se então como a cena de um crime ou de um ato sexual violento. Uma nova reviravolta na descrição

\footnotetext{
${ }^{1}$ Doutor em Filosofia pela Universidade Estadual de Campinas (UNICAMP). Professor do Departamento de Filosofia da Universidade Federal de São Paulo (UNIFESP). E-mail: lfgatti@ gmail.com.
} 


\section{Gatti, L. - Descrição de imagem, H. Müller}

faz surgir uma paisagem pós-apocalíptica, um cenário do eterno conflito entre vivos e mortos. O texto passa então à consideração crítica do trabalho descritivo e dos traços amadores do desenho. Por fim, aquele que descreve também aparece na imagem, espelhando-se nos personagens e perturbando a distância entre imagem e observador. Müller constrói o texto de forma a abalar a distinção rígida entre a originalidade do desenho e o caráter secundário da atividade literária. Os elementos surgem e desaparecem à medida que são descritos, ganham forma, e dão lugar a novas imagens, sucessivamente colocadas em questão pela escrita. Ao comentar o texto em sua Autobiografia, Müller evoca esse processo.

Descrever uma imagem também é retocá-la com a escrita. A descrição a traduz em outro medium. Árvore, mulher, homem e casa eram os pontos de apoio do desenho. Dava pra fazer um redomoinho com isso, pois havia os pontos de apoio. A estrutura do texto reside em que uma imagem coloca a outra em questão. A cada vez uma camada apaga a anterior e a perspectiva (óptica/Optiken) muda. No final, o próprio observador é colocado em questão, e assim também quem descreve a imagem (MÜLLER 2008: 269).

A transposição do medium visual para a escrita resulta num gênero singular: uma frase única, com redução extrema das convenções teatrais, e ainda assim um texto concebido para o teatro. Em uma entrevista, Müller define Descrição de imagem como um "ponto final ou ponto zero" (MÜLLER 1986: 184). A expressão não deve ser entendida como o termo final de um processo teleológico, iniciado na década anterior, de eliminação de convenções dramáticas como fábula, ação e diálogo, mas como o exemplo mais radical de uma dramaturgia voltada ao questionamento das condições existentes para a prática teatral. ${ }^{2}$ Descrição de imagem poderia ser associado a outros exemplos na fronteira entre a prosa e as artes visuais, tais como o teatro de Robert Wilson, ${ }^{3}$ com o qual Müller colaborou intensamente nos anos 1980, com as peças-paisagem de Gertrude Stein (Cf. JOURDHEUIL 2005: 41) e com os trabalhos tardios de Samuel Beckett. ${ }^{4}$ O texto já foi classificado por Hans-Thies Lehmann (2002: 340-343) como pós-dramático, mas seria mais bem entendido como uma "explosão de uma recordação numa estrutura dramática morta", como define a nota do autor (cf. MüLLER 1999: 119; MÜLLER 1993: 159). Em

\footnotetext{
2 "A literatura está aí para oferecer resistência ao teatro. Um texto só é interessante ou produtivo para o teatro quando ele não pode ser feito do modo como o teatro é concebido." (MÜLLER 1986: 18). Quando não houver indicação de tradução brasileira, as traduções dos textos citados são de minha autoria.

${ }^{3}$ Sobre Müller e Bob Wilson, Cf. LeHMANN (2005: 64-6) e BonNAud (2005: 137). Um mapeamento abrangente da bibliografia secundária sobre Descrição de imagem pode ser encontrada em SCHÜTTE (2010: 257-316).

${ }^{4}$ Sobre Müller e Beckett, cf. BIRKENHAUER (2005b: 214) e KALB (1998: 171-2).
} 


\section{Gatti, L. - Descrição de imagem, H. Müller}

outras palavras, uma evocação do gênero dramático sob o signo da impossibilidade das convenções clássicas, em busca de outras formas de conflito dramático, como aquela entre imagem e descrição.

Ainda na Autobiografia, Müller extrai do amadorismo do desenho "espaços livres para a fantasia”, expressão essa que ultrapassa o domínio da escrita e reverbera na posição do espectador:

Eu comecei a descrever a imagem. Aí surgiram associações com a imagem que partiam essencialmente das incorreções do desenho, os erros eram espaços livres para a fantasia. [...] Nesse sentido, ela é um autodrama, uma peça em que o autor encena consigo mesmo, atua consigo mesmo. O autor torna-se seu próprio ator e diretor. Em Descrição de imagem trata-se do seguinte: qualquer um consegue fazer aquilo, de um modo mais ou menos bom e cada um de uma maneira diferente. A arte mais avançada é a mais democrática, qualquer um pode descrever uma imagem, a descrição produz novas imagens quando se escreve junto o que lhe ocorre durante a descrição. É um modo de encenação disponível a todos que conseguem ver e escrever (MÜLLER 2008: 269-270).

O formato inusitado da descrição é um ensejo à liberdade do espectador. Pode causar estranheza que Müller defenda um de seus trabalhos mais herméticos pelo caráter democrático da forma. A proposta é ousada e remete à ideia de autodrama. O conceito é novo em sua produção, mas perfeitamente situável no contexto de seu enfrentamento do modelo brechtiano da peça de aprendizagem, ainda que o confronto com temas e recursos formais de $A$ medida (1930) de Brecht não seja explícito como em sua versão do Material Fatzer (1979) e em peças como Mauser (1970) e Quarteto (1980). ${ }^{5}$ Encenar uma peça consigo mesmo: evoca-se aqui o modelo segundo o qual todo participante pode assumir os papéis de autor, diretor e espectador. Como no experimento brechtiano, o rompimento com a divisão de trabalho entre produtores e receptores remete à reconfiguração da vida em sociedade.

Em Descrição de imagem, a visada emancipatória da forma, que aponta para além de um dado estado de coisas, configura-se pela atuação recíproca de imagem e descrição. Como se verá pela análise do texto, o movimento do texto é produzido pelo esforço incessante da descrição em modificar a imagem, não apenas o desenho tomado como ponto de partida, mas também aquelas imagens produzidas pela descrição. Vejamos o início:

\footnotetext{
${ }^{5}$ Para uma interpretação de A medida, cf. GATTI (2011). Uma análise de minha autoria da versão de Müller para o Fatzer de Brecht será publicada ainda em 2013 no número 14 da revista Artefilosofia da Universidade Federal de Ouro Preto.
} 


\section{Gatti, L. - Descrição de imagem, H. Müller}

Uma paisagem entre estepe e savana, o céu de um azul prussiano, duas nuvens imensas flutuando lá dentro, como que unidas por esqueletos de arame, em todo caso de estrutura desconhecida, a maior, da esquerda, poderia ser um animal de borracha de um parque de diversões que se desgarrou de seu guia, ou um pedaço da Antártida em seu voo de regresso, no horizonte uma serra plana, à direita na paisagem uma árvore, num olhar mais preciso são três árvores altas distintas em forma de cogumelo, tronco com tronco, talvez de uma raiz, a casa no primeiro plano mais produto industrial que manual, provavelmente de concreto: uma janela, uma porta, o telhado coberto com a folhagem da árvore em frente que cresce sobre a casa, ela pertence a uma outra espécie que o grupo de árvores no plano posterior, seu fruto é aparentemente comestível, ou próprio para envenenar convidados [...] (MÜLLER 1999: 112; MÜLLER 1993: 153)

O início do texto se assemelha ao gênero da écfrase, à descrição detalhada de um objeto situado diante do observador. ${ }^{6}$ A imagem é descrita no tempo presente, com emprego econômico dos verbos e uso abundante de termos que permitem aproximações, como "entre", "como que”, “em todo caso", "talvez", "aparentemente", "provavelmente”, bem como pelo uso da conjunção "ou”, aqui e na sequência do texto. Tais escolhas buscam reservar uma margem de possibilidades diante da incerteza a respeito dos elementos descritos, a qual pode derivar tanto da imperfeição da imagem quanto da posição do observador. Vê-se assim que a recepção da imagem é um momento inerente à atividade de descrevê-la, o que se evidencia pela evocação do olhar que a perscruta em distintas aproximações. Nesse sentido, a descrição incorpora a diferenciação entre uma provável primeira impressão e o exame posterior mais cuidadoso ("um olhar mais preciso") e confessa uma limitação objetiva em desvendar os objetos retratados ("em todo caso de estrutura desconhecida").

A descrição prossegue pelas frutas e pela taça de vinho sobre a mesa e, da posição dessa, chega-se a uma questão decisiva para a relação entre imagem e descrição:

Pela posição da mesa [...] pode-se concluir que o sol, ou seja, o que for que lança luz sobre esse lugar, no momento da imagem está no zênite, pode ser que o SOL esteja lá sempre e NA ETERNIDADE: que ele se movimente não se pode provar pela imagem, as nuvens também, se é que são nuvens, flutuam talvez no lugar (MÜLLER 1999: 112; MÜLLER 1993: 153-4)

Essa passagem qualifica temporalmente os dados apreendidos no interior da circunscrição espacial da imagem, seja ela a paisagem figurada, seja a circunscrição

\footnotetext{
${ }^{6} \mathrm{O}$ vínculo entre tableau e ação dramática, tal como discutido por Diderot, também foi lembrado por KEIM (1998: 125) e HEEG (2005: 158).
} 


\section{Gatti, L. - Descrição de imagem, H. Müller}

material da imagem (como as margens de uma tela ou de uma folha de papel). A essa espécie de natureza morta é atribuída a distinção da eternidade. Por ter sua origem no sol posicionado no zênite, a eternidade também se refere à iluminação absoluta dos elementos da imagem. Como mostrará a sequência do texto, o sol na eternidade assinala o objeto de embate para a descrição, que a partir de então se voltará contra o responsável por fazer da paisagem uma Paysage sous surveillance, como a qualifica o título da tradução francesa de Jean Jourdheuil. ${ }^{7}$ Quando a descrição passa rapidamente pelo pássaro na árvore ("num galho de árvore um pássaro, a folhagem encobre sua identidade, pode ser um abutre ou um pavão ou um abutre com cabeça de pavão, olhar e bico apontados para uma mulher" (MüLLER 1999: 112; MÜLLER 1993: 154)) e se volta para a mulher e para o homem, seu caráter até então estático, ainda que relativizado pela incerteza a respeito das coisas, começa a alterar-se:

[...] uma mulher que domina a metade direita da imagem, sua cabeça divide as montanhas, o rosto é suave, muito jovem, o nariz longo demais, um inchaço na base, talvez de um soco, o olhar no chão, como se não pudesse esquecer uma imagem e ou não quisesse ver outra, o cabelo comprido de mechas, loiro ou cinza esbranquiçado, a luz dura não diferencia (MÜLLER 1999: 114; MÜLLER 1993: 154)

A descrição segue o exame minucioso dos objetos em vista, oscilando entre o limite da observação ("a luz dura não diferencia") e a especulação a respeito do que a imagem não informa ("talvez de um soco"). Esse uso do "talvez", porém, diferencia esse trecho do anterior, pois remete à busca de uma conexão do momento fixado pela imagem com momentos passados, a qual é explicitada na sequência:

[...] ergue uma mão à altura do coração, ou seja do peito esquerdo, um gesto de defesa ou da língua dos surdos-mudos, a defesa vale um horror conhecido, o golpe empurrão estocada aconteceu, o tiro disparado, a ferida não sangra mais, a repetição cai no vazio, onde o pavor não tem lugar, o rosto da mulher torna-se legível, se a segunda suposição for correta, um rosto de rato, um anjo dos roedores, os maxilares moem cadáveres de palavras e detritos de fala, a manga esquerda do casaco dependurada em farrapos como após um acidente ou agressão de algo dilacerante, animal ou máquina, curioso que o braço não foi ferido, ou as manchas marrons na manga são sangue coagulado, o gesto da mão direita de dedos longos vale uma dor no ombro esquerdo, o braço tão solto dependurado na manga, porque ele está quebrado, ou uma ferida na carne o paralisou (MÜLLER 1999: 114; MÜLLER 1993: 154)

\footnotetext{
${ }^{7}$ Sobre o comentário do tradutor a respeito dessa escolha, cf. JOURDHEUIL (2005). Para uma analogia com o panóptico de Bentham discutido por Foucault em Vigiar e Punir, cf. HAß (2005).
} 


\section{Gatti, L. - Descrição de imagem, H. Müller}

Nessa passagem, a descrição não se orienta mais pelo detalhamento das particularidades de um objeto situado perante um observador. A partir daqui, ela se torna uma consideração a respeito do vir a ser da imagem, remetendo a uma hipotética origem da cena pela articulação entre os dados observados e a suposição de eventos passados. Contra o sol no zênite, a descrição inscreve a imagem no transcurso temporal, com o intuito de explicitar o que a imagem não mostra sob a eterna visibilidade. Além disso, ela também desafia seus limites espaciais, questionando o que se encontraria para além da moldura: “o braço está cortado no pulso pela borda da imagem, a mão pode ser uma garra, um coto (talvez com sangue ressecado) ou um gancho, a mulher está até os joelhos sobre o nada, amputada pela borda da imagem, ou ela cresce do solo" (MüLLER 1999: 113; MÜLLER 1993: 154).

Em um artigo influente sobre Descrição de imagem, Hans-Thies Lehmann, ao propor uma divisão do texto, considera esses momentos iniciais como um único bloco, responsável pela apresentação dos elementos em cena (LEHMANN 2005: 80). A observação merece reparo, pois Müller diferencia nitidamente a descrição dos componentes naturais, fixados pelo sol da eternidade, da descrição da mulher, ponto a partir do qual a descrição passa a operar em registro temporal e fabulador. A distinção é necessária para que os personagens não se naturalizem como dados de uma mesma história natural. A visão da história como natureza, segundo a qual a possibilidade de irrupção do novo no curso dos eventos da história humana dissolve-se na repetição de um ciclo natural, marcado por decadência, opressão e morte, é essencial à maneira como Müller concebe a história europeia. Ele compartilha o olhar melancólico do alegorista barroco descrito por Benjamin, que vê a história como "paisagem originária petrificada". Descrição de imagem é legível nesse contexto, mas também aponta para além dele. $\mathrm{O}$ sol na eternidade confere à história o aspecto de uma ruína. $\mathrm{O}$ trabalho da descrição, contudo, insere a paisagem em uma dinâmica temporal, que traz à tona a história de violência de todos contra todos como condição para o rompimento com a circunscrição da imagem. Só nesse novo contexto seria possível evocar uma história comum a todos os elementos da paisagem, tal como Müller formulou em um texto sobre sua colaboração com Bob Wilson em CIVIL warS (1984):

O fantasma tem o horror sob a pele. Seu teatro é a ressurreição. A libertação dos mortos ocorre na lupa do tempo. Com a sabedoria dos contos de fada de que a história da humanidade não pode mais ser superada da história dos animais, das plantas, das pedras 


\section{Gatti, L. - Descrição de imagem, H. Müller}

e das máquinas sob o preço da derrocada, CIVIL warS formula o tema da época: guerra de classes e raças, espécies e gêneros, guerra civil em todos os sentidos (Apud LEHMANN 2005: 65). ${ }^{8}$

O surgimento de esboços de narrativa em meio à descrição deve ser entendido por via do contraste entre o momento dinâmico da descrição, fabulador, inclusive, e o caráter inicialmente estático do desenho. A coordenação desses polos, contudo, não é simples, pois a descrição não visa à mera subsunção da cena no transcurso de uma ação que a explique. Na sequência da descrição da mulher, o texto volta-se para o homem na soleira da porta da casa, segurando um segundo pássaro morto na mão e questiona "o que vai acontecer na mesa de pernas cruzadas" no jardim (MÜLLER 1999: 115; MüLLER 1993: 155). O movimento indica o retorno ao jardim onde se encontra a mulher, mas a descrição remete novamente ao passado. Ela parte do estado das cadeiras como indícios de uma ação passada para reconstituí-la: "que peso quebrou a cadeira, desestabilizou a outra, um assassinato talvez, ou um ato sexual selvagem, ou os dois em um” (MüLLER 1999: 115; MülLER 1993: 155). Palavras-chave como "talvez" e "ou" sustentam o caráter hipotético do registro narrativo, sem vincular o dado presente a uma única cadeia de eventos. Ao contrário, a especulação fabuladora não exclui nenhum termo da equação e expande o campo de possibilidades narrativas. A primeira delas descreve o ato sexual:

[...] o homem na cadeira, a mulher sobre ele, o membro dele em sua vagina, a mulher ainda carregada do peso da terra do túmulo de onde saiu para visitar o homem, da água subterrânea que seu casaco de pele escorre, seu movimento primeiro um balançar suave, depois um cavalgar impetuoso e progressivo, até que o orgasmo comprime as costas do homem contra o espaldar da cadeira, que cede estalando, as costas da mulher contra a quina da mesa derrubando o copo de vinho (MÜLLER 1999: 115; MÜLLER 1993: 155)

A segunda, o assassinato por estrangulamento: "ou a mulher na cadeira, o homem de pé atrás dela, polegar com polegar as mãos dele em volta do pescoço dela” (MüLLER 1999: 115; Müller 1993: 155). Na sequência, uma facada no pescoço: "ou a sombra esfiapada no pescoço da mulher abaixo do queixo provém de um corte de faca" (MÜLLER 1999: 115-6; MüLLER 1993: 156). Por fim, a quarta hipótese exclui o homem da cena, deixando a mulher às voltas com o pássaro: “ou será a mulher, o anjo sedento, que abre a mordidas a goela do pássaro e derrama no copo o sangue de sua garganta

\footnotetext{
${ }^{8}$ Cf. também MÜLleR 1990: 109-110; MÜLLER 2008: 257-263; e MÜLLER 2005b: 315-318.
} 


\section{Gatti, L. - Descrição de imagem, H. Müller}

aberta, o alimento dos mortos" (MÜLlER 1999: 116; MÜLLER 1993: 156). Nenhuma é mais plausível ou completa que a outra. Também não há relação de subordinação que permita encadeá-las na composição de uma ação. A descrição, ao contrário, assume um caráter eminentemente paratático, especulando com narrativas possíveis, de modo a resguardar a potencialidade semântica de seu ponto de partida.

Com o intuito de explicitar as consequências do modo paratático de descrição, vale a pena lembrar, juntamente com Theresia Birkenhauer, que Descrição de imagem desafia uma longa tradição que diferenciou as artes visuais da poesia por meio das relações entre espaço e tempo, uma tradição que tem no estudo de Lessing sobre o Laocoonte sua maior referência (cf. BIRKENHAUER (2005: 93-6) e também KEIM (1998: 125-6). Como se sabe, Lessing confere especificidade às artes visuais ao defini-las como artes do espaço, por oposição ao caráter temporal da poesia. Pela oposição entre evento temporal e objeto estático, as diferentes partes da composição de um objeto visual devem ser apresentadas ao espectador conjuntamente, de modo a serem apreendidas ao mesmo tempo. Essa distinção um tanto rígida é, porém, amenizada pelo reconhecimento de que também os corpos existem no tempo, aparecendo de modos distintos conforme as circunstâncias. O caráter inicialmente estático do objeto é então temporalmente qualificado como um instante de sua existência temporal, o qual decorre de circunstâncias anteriores e pode vir a ser causa de eventos posteriores. Com isso, Lessing insere toda aparição momentânea no decurso de uma ação temporal e daí extrai uma instrução normativa para as artes visuais: a obra de arte visual, pela coexistência das partes em suas composições, só pode valer-se de um único momento da ação, e por isso deve escolher o mais pregnante, o mais sugestivo do que veio antes e do que deve vir depois. E vinculando a representação visual ao "momento pregnante", Lessing está nitidamente defendendo o caráter narrativo da representação dos corpos nas artes visuais e, não menos importante, restringindo tal caráter narrativo, de modo muito clássico e aristotélico, à composição de uma ação inteira e acabada, cujas partes se articulam por relações de causa e efeito, e cujo decurso tende à resolução que confere sentido retrospectivo aos eventos narrados.

Diante desse quadro, é possível dizer que Descrição de imagem distancia-se da distinção proposta por Lessing por refutar a ideia do "momento pregnante" de uma ação. A descrição de Müller recusa a articulação orgânica entre instante e todo, optando 


\section{Gatti, L. - Descrição de imagem, H. Müller}

por explorar a produtividade semântica da justaposição de narrativas. Pelo trabalho de descrição, surgem fragmentos de ações possíveis, mas nenhuma delas fecha o círculo da ação inteira e acabada. Por motivos semelhantes, Descrição de imagem também escapa à célebre alternativa proposta por Lukács entre "narrar ou descrever" (LUKÁCS 1955). No texto de Müller, descrever não se entende por referência à literatura de tendência naturalista, voltada ao registro exaustivo de detalhes. E narrar, por sua vez, também não se conforma aos parâmetros hegelianos da composição da ação e do desenvolvimento do caráter. O trabalho de Müller vincula descrição e narração de modo que o combate ao instante de eternidade de uma imagem, seja ele definido por seu caráter estático, seja pela presunção de visibilidade plena das figuras apresentadas, atinja também o pressuposto do momento pregnante, a saber, a subsunção do particular ao todo da ação.

É o que permite que Descrição de imagem evoque formas de percepção de imagens ausentes do estudo de Lessing, como o piscar de olhos.

Ele [o piscar de olhos] permite perceber o que não é visível nos limites de um contínuo temporal. [...] O piscar de olhos exclui o visível, leva além da imagem, supõe o movimento que destrói a moldura em um abalo oculto ao olhar. Só a interrupção, o fechar os olhos 'entre dois olhares', torna possível perceber, o que não está para ser visto na imagem, mas o que a imagem indica (BIRKENHAUER 2005b: 97).

Quando os olhos se fecham, a paisagem se altera:

[...] quando o olho VIU TUDO pestanejando se fecha sobre a imagem, entre árvore e mulher a única e grande janela toda aberta, a cortina esvoaçando para fora, a tempestade parece sair da casa, nas árvores nenhum sinal de vento, ou a mulher atrai a tempestade que esperava por ela na cinza da lareira, ou a chama com sua aparição (MÜLLER 1999: 113-4; MÜLLER 1993: 154).

Ao subverter a relação entre visível e invisível na percepção da imagem, o piscar de olhos confere um novo impulso à descrição. A imagem anterior da mulher "carregada do peso da terra do túmulo de onde saiu para visitar o homem", "talvez diariamente ressurrecta", que impunha ao homem o trabalho do homicídio diário, ressurge agora sob o signo da tempestade, fazendo da imagem a paisagem histórico-filosófica de uma catástrofe pós-apocalíptica. Como uma representante do mundo dos mortos, ela aparece "grávida pela tempestade": "quando todos estiverem mortos, o movimento dos túmulos na fúria da ressurreição, que expulsa as cobras da montanha, será a mulher furtiva e de 


\section{Gatti, L. - Descrição de imagem, H. Müller}

boca de ventosa uma MATA HARI do mundo subterrâneo, espiã que sonda as terras onde acontecerá a grande manobra” (MüLLER 1999: 117; MÜLLER 1993: 157).

O tema do mundo dos mortos tem ressonâncias explícitas na nota do autor: aparece no mito de Alceste, com retorno da mulher morta, e na descida de Ulisses ao reino dos mortos no Canto XI da Odisseia. Como lembra Lehmann (2005: 79), o tema também evoca os mortos de Shakespeare, que vivem entre dois mundos, como fantasmas de uma história ainda não consumada. ${ }^{9} \mathrm{O}$ trabalho com os mortos merece ainda a autocitação de uma passagem de Mauser (1970) para descrever o trabalho do assassino: - "inútil arrancar a grama, o sol ou uma multiplicidade de sóis a queima". Na peça de 1970, "arrancar a grama" remetia à conversão do trabalho revolucionário em tarefa infinita de liquidação de seus inimigos. A conjunção entre trabalho, morte e revolução apontava para a perda de sentido do processo histórico revolucionário, o qual não se justificava mais perante seus agentes. Sob o signo do "sol" ou de uma "multiplicidade de sóis", Descrição de imagem retoma tal visão da história como repetição de um eterno conflito entre vivos e mortos: "um DEDO PERVERSO que os mortos seguram ao vento contra a polícia do céu, antecessora e NOIVA DO VENTO, que estira o vento onde habitam os inimigos naturais da ressurreição da carne" (MÜLLER 1999: 117; MÜLLER 1993: 157).

A referência intertextual a Mauser exerce aqui a função de uma advertência: ela ressalta que o sol permanece uma ameaça a despeito do surgimento de outra visão da paisagem com o piscar de olhos. Esse movimento instável da relação entre descrição e imagem torna a contestação do instante eterno tão precária quanto incessante, permitindo supor que narrativa alguma é suficiente para assumir o lugar da imagem. Daí o esforço da descrição em ultrapassar o domínio da paisagem descrita para atingir, por uma nova reviravolta, os dados materiais da composição do desenho:

[...] ou tudo é diferente, a rede de aço o humor de um lápis descuidado, que nega a plástica das montanhas com um sombreado mal executado, talvez a arbitrariedade da composição siga um plano, a árvore sobre uma bandeja, as raízes cortadas, as árvores de outro tipo ao fundo são cogumelos de caule singularmente longos, vegetal de zona climática que não conhece árvores, como o bloco de cimento entrou na paisagem, nenhum vestígio de transporte ou veículo (MÜLLER 1999: 118; MÜLLER 1993: 157-8).

\footnotetext{
${ }^{9}$ Sobre Alceste, cf. o comentário de KEIM (1998: 142), segundo o qual, diferentemente do que ocorre na tragédia de Eurípedes, em Descrição de imagem, o retorno da mulher não indica reconciliação, mas a infinitude do círculo de violência na história, a qual tem continuidade com o retorno dos mortos. Cf. também o artigo de HAHN (2005).
} 


\section{Gatti, L. - Descrição de imagem, H. Müller}

A tematização da produção submete a imagem a um distanciamento desnaturalizador. A descrição descobre que as imperfeições escondem a presença humana na paisagem, como se seus elementos tivessem "caído do CÉU, ou baixado com garra mecânica do ar respirável só pelos mortos e que é movida a partir de um ponto fixo no CÉU chamado além” (MÜLLER 1999: 118; MÜLLER 1993: 158). Juntamente com o aspecto de artefato, também vem à tona a interrogação a respeito de um plano orientando a composição, o que justificaria a designação da imagem como uma "ordenação experimental":

[...] a imagem uma ordenação experimental, a rudeza do esboço uma expressão do desprezo pelas cobaias homem, pássaro, mulher, a bomba sanguínea do homicídio diário, homem contra pássaro e mulher, mulher contra pássaro e homem, pássaro contra mulher e homem, abastece o planeta com combustível, sangue a tinta, que descreve em cores sua vida de papel, seu céu também ameaçado de anemia pela ressurreição da carne (MÜLLER 1999: 118; MÜLLER 1993: 158)

O conceito de ordenação experimental fora cunhado por Benjamin para apresentar o modo pelo qual os procedimentos formais do teatro épico brechtiano lidavam com a realidade. Crítico das representações naturalistas ou naturalizantes, o teatro épico deveria mostrar ao espectador o mundo de maneira estranha, de modo que esse espectador fosse levado a espantar-se diante do que via e interrogar o caráter artificial, histórico e, portanto, transformável das situações apresentadas. Em outras palavras, o teatro épico deveria produzir uma imagem praticável da realidade, ou seja, uma imagem capaz de mostrar a possibilidade de intervir nessa realidade. Essa imagem foi referida por Benjamin como uma ordenação experimental por oposição à reprodução naturalista da realidade. A retomada do termo chama a atenção, pois a finalidade prática atribuída ao teatro épico parece estranha a uma visão da história como paisagem apocalíptica, "vista de além túmulo", como Müller a designa em nota ao texto. A visão da guerra de todos contra todos, cujo sangue é o alimento da própria escrita ("sangue a tinta"), poderia ser lida em sentido crítico às expectativas práticas associadas ao teatro brechtiano. Muitas das reflexões de Müller a respeito do fim de um modelo europeu de revolução, com a consequente entrada do curso da história em estado de hibernação, embasariam tal afastamento de Brecht. Essa posição expressa em textos e entrevistas dos anos 1970, entre eles a carta a Steinweg de 1977 (MÜLLER 2005d: 187), é, contudo, relativizada por outros textos. Em uma entrevista dada pouco tempo após a escrita de Descrição de imagem, ele afirma: 


\section{Gatti, L. - Descrição de imagem, H. Müller}

Aprender algo, isso só é possível em situações em que algo se move na história. Quero dizer que agora algo se move, algo tem que se mover. A situação está madura para transformações. Esse é o momento em que de novo se pode aprender, em que se deve aprender. Por isso também essa forma de espetáculo da peça de aprendizagem se torna novamente atual (MÜLLER 1986: 189).

Essa posição explicita o conflito não resolvido em Descrição de imagem que justifica a referência à “ordenação experimental”. Comentadores como LEHMANN (2005: 68), BIRKENHAUER (2005b: 96) e KEIM (1998: 123) ressaltaram a configuração de um drama entre imagem e descrição, um conflito que se configura de modo mais amplo na oposição entre o olhar da visibilidade completa, que enrijece a paisagem sob o sol na eternidade, e a intermitência do piscar de olhos, da visibilidade fugidia do momento apreendido entre dois olhares. O piscar de olhos traz consigo a aspiração por uma utopia que poderia ser referida como a libertação em relação à imagem da eternidade. Ele também pode ser descrito com as palavras do próprio Müller ao referir-se ao teatro de Bob Wilson: "O tempo é um momento principal no teatro de Wilson. Ele se interessa pelo momento entre dois olhares, pelo quê e como alguém vê durante um piscar de olhos" (MÜLLER 2008: 260). ${ }^{10}$ Tal olhar desata um processo narrativo que nunca se totaliza. Nesse sentido, vê-se que a narrativa é inserida para que dela possa emergir a interrupção, a hesitação, o instante fugaz, que não perdura, mas surge e desaparece num relampejar. É assim que a descrição assume a tarefa de buscar um erro na composição da imagem: "o vão no escoamento, o outro no retorno do mesmo, o gaguejar no texto sem fala, o buraco na eternidade, o ERRO talvez redentor" (MüLLER 1999: 118; MÜLLER 1993: 158). A busca por uma forma de alteridade na imanência da imagem remete à interrupção como seu modo temporal e ao erro como aspecto formalizador. Seguindo o comentário de LEHMANN, temos aqui três imagens do tempo:

\footnotetext{
${ }^{10}$ Em uma entrevista de 1988, Müller associa a importância da segmentação do tempo à onipresença da imagem na experiência americana de Wilson. Ela tem sua origem na situação de um país de estrangeiros em que a imagem conquistou prioridade perante a língua como forma de comunicação e o cinema se impôs, muito mais que a literatura, como fonte da memória nacional. Daí a ocupação da fantasia por imagens, bem como a inexistência de imagens que não correspondam a um clichê. O processo que atinge em cheio a percepção da realidade se intensifica com a televisão e com o desenvolvimento da tecnologia nas salas de cinema. Em uma conversa com Müller, Wilson refere-se ao cinema 3D como a ilusão total. Daí a gradual substituição da realidade por sua reprodução. Um teatro tão calcado na imagem como o de Wilson, que trabalha exaustivamente com a segmentação do tempo, seria tanto uma resistência quanto uma contribuição a tal estado de coisas. Essa é a encruzilhada de seu teatro. Sua fraqueza, ou seja, a leveza das imagens, estaria sendo cada vez mais combatida por Wilson ao carregá-la com um "material pesado" trazido da literatura. O trabalho intensificado com material literário a partir dos anos 1980 - entre outros a colaboração entre Müller e Wilson em CIVIL warS - é visto como uma transformação positiva. (Cf. MÜLLER 1990: 109-110).
} 


\section{Gatti, L. - Descrição de imagem, H. Müller}

[...] o tempo como linha, como retorno circular e como superfície infinita da eternidade. Três fórmulas "u-tópicas" respondem a essas três imagens: não a negação da linha, mas uma fenda nela, a qual é um erro, o qual também é a micro interrupção do contínuo, a micro falta; Também não o cessar do eterno retorno, mas, na repetição mesma, o outro, a esperança de que no ritmo do mesmo a repetição mesma altere a qualidade do mesmo, talvez como dança, como felicidade erótica, como recuperação do perdido, como a possível dissolução da fronteira entre vivos e mortos no retorno do mesmo no círculo da natureza (LEHMANN 2005: 72). ${ }^{11}$

Na sequência do texto, o erro é descoberto na falha do olhar atento do assassino, falha essa que provoca uma reviravolta possível da cena anteriormente descrita:

[...] olhar distraído do assassino quando examina o pescoço da vítima sobre a cadeira com as mãos, com o gume da faca, sobre o pássaro na árvore, no vazio da paisagem, hesitação perante o corte, o jato de sangue fecha os olhos, riso da mulher, que por um instante afrouxa o estrangulamento, faz tremer a mão com a faca, voo mergulho do pássaro, engodado pelo brilho do gume, pouso sobre o crânio do homem, duas bicadas à direita e à esquerda, vertigem e urro dos cegos, sangue chispando no torvelinho da tempestade que procura a mulher (MÜLLER 1999: 118-9; MÜLLER 1993: 158).

Essa cena revela de maneira exemplar como o erro altera a imagem. Não por acaso ele surge como uma nova forma de percepção: o olhar distraído por oposição ao olhar atento. Por um instante, o olhar vigilante perde de vista a mulher sob seu domínio. Daí segue outro encadeamento de fatos: o olhar incomodado pelo sangue faz com que a mão hesite e afrouxe o pescoço da vítima; a risada desta faz a faca reluzir, atraindo o pássaro que cega o assassino e fecha o círculo que une a falha do olhar absoluto à sua cegueira. Trata-se de uma interrupção possível daquele trabalho eterno e repetido imputado ao homem, o "homicídio talvez diário da mulher talvez diariamente ressurrecta". O erro emerge do caráter hipotético desse "talvez", uma possibilidade assinalada na sua fragilidade, que convive entre a certeza do horror e a incerteza a seu respeito, entre a esperança e o "medo que o erro aconteça num piscar de olhos, a brecha de vista que se abre no tempo entre um olhar e outro, a esperança mora no gume de uma faca que com atenção crescente, logo fadiga, rota mais rápido, incertezas relampejantes na certeza do horror" (MÜLLER 1999: 112; MÜLLER 1993: 153). ${ }^{12}$

\footnotetext{
${ }^{11}$ Ao contrário do que sustenta EKE (1989: 247), a interrupção e o erro não remetem a uma ideia de utopia que só pode ser pensada na sua ausência: falhas no decurso. Ao contrário, ela está inscrita no texto como possibilidade, sem que para isso precise delinear um conteúdo concreto.

${ }^{12}$ Cf. o comentário de SCHNEIDER (2005: 116), para quem a função da descrição é evocar um estado de potencialidade, de não-atualidade.
} 


\section{Gatti, L. - Descrição de imagem, H. Müller}

A importância dessas passagens não se esgota em mostrar um novo encadeamento de fatos a partir da interrupção do olhar. Elas também são notáveis por não assinalar o erro na imagem inicialmente dada ao observador, mas em um momento posterior da descrição, quando se fabulava a respeito do vir a ser da cena no jardim. A descrição retorna a esse momento (passado?) em busca do "erro talvez redentor", produzindo uma nova imagem que coloca a anterior em questão. Tal seria a estrutura da descrição assinalada por Müller. Não se trata apenas de erros na imagem visual, mas também nas narrativas incorporadas à descrição. É possível dizer que, nesse ponto, a imagem subsiste apenas como imagem descrita, a qual conquista ao longo do processo um alto grau de reflexividade.

Seria então legítimo supor um plano atuante em tal ordenação experimental? Esse plano corresponderia à intenção de um autor soberano conduzindo a descrição? A posição do autor (observador/descritor/narrador) é uma das questões mais intrincadas desse texto hermético. De modo coerente com a estrutura autoreflexiva da descrição, tal posição também é submetida à averiguação. Nas palavras de Müller, "no final, o próprio observador é colocado em questão, e assim também quem descreve a imagem" (MüLlER 2008: 269). A questão já aparecia antes por meio da suspeita de que "a arbitrariedade da composição siga um plano". Agora, no final, a descrição revela que “pertence ao plano a fiscalização falha” (MÜLLER 1999: 119; MÜLLER 1993: 158). Não é possível, contudo, decidir se o erro resulta de uma intenção do autor, seja ele o desenhista ou descritor, ou se a composição (desenho ou fabulação) é um procedimento necessariamente falho ou sujeito à falha, cabendo à descrição descobri-la. As afirmações críticas a respeito das insuficiências formais do desenho, bem como a descoberta do erro em um momento anterior da descrição, tornam plausível a hipótese de que a descrição trabalha com os erros imanentes ao seu material. Em Descrição de imagem, a ideia de um erro objetivo, imanente à formalização artística, aponta para a lógica interna ao material artístico e estabelece uma configuração singular da relação entre sujeito e objeto. Ela vem à tona no momento final, com o aparecimento da figura de um "EU”, provável observador ou descritor da imagem.

[...] o HOMICÍDIO é uma troca de sexos, ESTRANHO NO PRÓPRIO CORPO, a faca é a ferida, a nuca o machado, pertence ao plano a fiscalização falha, em que aparelho está presa a lente que suga as cores do olhar, em que órbita ocular está estirada a retina, que OU O QUÊ pergunta pela imagem, MORAR NO ESPELHO, o homem com o 


\section{Gatti, L. - Descrição de imagem, H. Müller}

passo de dança EU, meu túmulo seu rosto, EU a mulher com a ferida no pescoço, à direita e à esquerda nas mãos o pássaro partido, sangue na boca, EU O PÁSSARO, aquele que com a escrita de seu bico mostra ao assassino o caminho na noite, EU a tempestade gelada. (MÜLLER 1999: 119; MÜLLER 1993: 158-9)

Vê-se aqui que a relação entre sujeito e objeto, entre quem observa ou descreve a imagem e a imagem observada, é um terreno instável. O texto aponta uma série de justaposições (faca-ferida; nuca-machado; túmulo-rosto), que leva ao confronto do "EU" com as figuras da imagem (homem, mulher e pássaro) e culmina na tempestade gelada. O autor aparece sob a figura desse "EU", como um produto de sua fabulação descritiva. Sua aparição coloca em questão a distinção inicial entre descrição e imagem, como se uma tivesse sido absorvida pela outra. Daí o surgimento de uma máquina de olhar, algo entre aparelho mecânico e olho humano, distinto ou síntese da relação entre sujeito e objeto, da qual resulta uma série de espelhamentos e aproximações entre o "EU" e as figuras da imagem descrita.

Diversos comentários ao texto identificam no momento final um questionamento da distinção clássica entre sujeito e objeto, produzindo interpretações que vão da concepção de um sujeito cindido entre dois olhares, incapaz de guardar distância do outro e definir-se como uma instância autônoma e autocentrada, como defende LEHMANN (2005), à dissolução da dicotomia por meio de uma ontologia da linguagem, como o faz BIRKENHAUER (2005b), movendo-se na vizinhança da tese da morte do autor, e caracterizando o "EU" como uma instância despersonalizada, anônima, não determinada ou determinável, que emerge pela primeira vez na escrita como metamorfose de todas as suas figuras. Enquanto Lehmann insiste na complexidade da relação entre sujeito e objeto por meio da dissolução de oposições enrijecidas que demarcavam com nitidez os limites entre o "EU" e as figuras que o circundam, Birkenhauer julga dar um passo além, ao afirmar a autoprodutividade da linguagem, irredutível a qualquer subjetividade autoral, como se dela emergisse um termo comum, terceiro ou neutro, síntese ou alteridade em relação a essa dicotomia. ${ }^{13}$

A tentativa de solucionar (e não apenas o teor da solução) um problema tensionado até o fim por meio do conflito entre as duas formas de olhar, entre EU e as figuras da imagem, torna a interpretação de Birkenhauer difícil de sustentar. A leitura de Lehmann, por sua vez, escrita bem antes da publicação de sua teoria do Teatro pós-

\footnotetext{
${ }^{13}$ No mesmo sentido, cf. SCHÜTTE (2010: 300).
} 


\section{Gatti, L. - Descrição de imagem, H. Müller}

dramático, é mais coerente com o conflito interno ao texto, embora necessite justificarse em um esboço pós-moderno do fim de uma concepção de sujeito autocentrado, idêntico a si mesmo, e de uma ideia de história pautada pelo progresso. Daí o feitio do texto como dramatização de uma paisagem da consciência, na qual a interrupção, o erro e a não-identidade surjam tanto como ameaça de dissolução do sujeito quanto como figuras utópicas perante um contínuo de dominação. A verdadeira teatralidade do texto resultaria dessa dramatização da subjetividade cindida, cujas contradições, fantasias e recordações se autonomizariam como protagonistas de uma cena de violência que destrói o "EU" e a moldura da imagem.

Diante da complexidade do texto, o ponto de fuga pós-moderno de Lehmann soa como uma resposta fácil. Seria mais interessante observar como o "aparelho" de Müller e sua paisagem varrida pela tempestade congelada lidam com problemas e aporias herdadas da tradição teatral a qual ela se reporta e reformula. Nesse contexto, o confronto do conceito de autodrama com o modelo da peça de aprendizagem é revelador. No experimento brechtiano, cada participante realizava um transcurso entre sua identidade como ator e os papeis representados. A não-identidade entre esses dois polos permitiria o aprendizado com as posições representadas por cada personagem. A passagem pelo personagem e o retorno a si, em um jogo configurado pelas polaridades de identificação/empatia e distanciamento/estranhamento, resultava num modo de atuação com potencialidade esclarecedora. $\mathrm{O}$ confronto com situações de "estranhamento" certamente não era um privilégio do teatro brechtiano. Como ele mesmo reconhece, o artifício estava presente em outras vanguardas artísticas como o dadaísmo e o surrealismo, para não falar de Kafka, que também buscavam perturbar a aparência habitual das coisas. O sucesso do "efeito de estranhamento" como artifício pedagógico dependia, contudo, de uma condição, elucidada por Brecht em um de seus textos teóricos: "O Dadaísmo e o Surrealismo usam efeitos de distanciamento do mais extremo tipo. Seus objetos não retornam de volta do distanciamento/estranhamento. $O$ efeito clássico de distanciamento produz uma compreensão/um entendimento mais elevado" (BRECHT 1967: 364). ${ }^{14}$ Não há dúvida aí de que Brecht se coloca nitidamente ao lado do efeito "clássico", o qual se sustenta no uso do entendimento e resulta em um conhecimento prazeroso das coisas. Ao mostrá-las como estranhas, de modo que atores

\footnotetext{
${ }^{14}$ Aproveito a citação de um artigo de Gagnebin (2002), do qual também retomo a interpretação proposta.
} 


\section{Gatti, L. - Descrição de imagem, H. Müller}

e espectadores se espantem com a evidência, com a "naturalidade" das situações habituais, o teatro também cria as condições para a "compreensão mais elevada", uma expressão que, de modo algum, aponta para um conhecimento desinteressado, mas, em última instância, para a compreensão da possibilidade de transformação de um estado de coisas.

Nas conversas de Svendborg com Walter Benjamin, Brecht evidencia seu desconforto com a estranheza provocada pelas narrativas de Kafka. O caráter enigmático, resistente à interpretação, dificultaria o vínculo, certamente problemático, mas ainda almejado por Brecht, entre a atividade artística e a vida prática. É o que explica seu desconforto com o ensaio de Benjamin sobre Kafka e a urgência em fornecer interpretações alegóricas para um romance como O Processo, de modo a extrair dali uma "imagem praticável do mundo" (cf. BENJAMIN 1991: 525-530). Quando Müller retoma esse debate em 1979, no ensaio "Fatzer \pm Keuner", seu ceticismo perante as pretensões pedagógicas do teatro brechtiano é acompanhado pela valorização do hermetismo da parábola kafkiana: "ela descreve/apresenta gestos sem sistema referencial e não é orientada por um movimento (práxis), irredutível a um significado, antes estranha que estranhadora, sem moral" (MüLlER 2005c: 224; MüLlER 2003: 50). Diante da alternativa colocada por Brecht acima, seria possível dizer que Müller assume uma posição nitidamente crítica perante o efeito "clássico" de estranhamento, alinhando-se ao "mais extremo tipo", em que as coisas podem permanecer estranhas. Seu hermetismo seria mais adequado a um momento de conexões avariadas entre experimentação artística e transformação social coletiva, uma vez que os “desmoronamentos da história recente causaram menos danos ao modelo da 'Colônia Penal' do que à construção dialética ideal das peças de aprendizagem" (MüLLER 2005c: 224; MÜLLER 2003: 50). Dado o feitio autoreflexivo do ensaio, poderíamos reconhecer em sua produção tardia, particularmente em Descrição de imagem, um exercício do "mais extremo tipo" de estranhamento. É assim revelador que Descrição de imagem termine por apresentar a figura da convivência entre o mais distante, a estranheza ou o estranho (Fremd), e o mais próximo e íntimo (Eigenen), ou seja, um "ESTRANHO NO PRÓPRIO CORPO (FREMD IM EIGENEN KÖRPER)", mas ainda assim um "EU", espelhado em suas múltiplas figurações e confrontado com a alteridade da imagem de si. 


\title{
Gatti, L. - Descrição de imagem, H. Müller
}

Esse tipo de estranhamento termina por colocar em questão a posição conferida pelo teatro épico ao espectador. Müller pronunciou-se diversas vezes contra o direcionamento da recepção pela teoria do teatro épico, a qual teria se imposto pelo caráter fechado da parábola.

\begin{abstract}
As peças-parábola de Brecht [...] são enormemente calculadas, produzidas como formações fechadas. [...] Para mim, ele transformou suas experiências frequente e rápido demais em juízos teóricos. Isto encurta o processo de recepção. [...] Um problema das peças tardias de Brecht: deixa-se pouca escolha ao espectador perante a teoria de Brecht. Em muitos aspectos, a teoria é mais avançada que a práxis. E também a concepção do teatro épico parte, na verdade, de dar um espaço de maior liberdade ao espectador perante o que é encenado, de avaliar o desenvolvimento dos personagens de modo distinto daquele com o qual o palco os avalia (MÜLLER 1990: 54-5).
\end{abstract}

Diante disso, é razoável supor que ele tenha escrito Descrição de imagem levando em conta a liberdade do espectador pretendida pela concepção do teatro épico, mas dificultada pelo comprometimento da parábola com a teoria de Brecht. Sem rubricas ou indicações de encenação ("a ação é livre”, diz a nota de Müller), Descrição de imagem prefigura modos de recepção ativados pela leitura cerrada, pelo trânsito entre escrita literária e escrita visual, pela escuta atenta de uma locução cujo ponto de apoio não é necessariamente a identidade de uma personagem. ${ }^{15} \mathrm{O}$ arranjo esquiva-se à transmissão de um produto acabado e exige do espectador o trabalho da imaginação como contrapartida. A recepção mimetizaria o processo de descrição, composição e questionamento das imagens e de seu observador/descritor, um processo definido por Müller como autodrama:

[...] uma peça em que o autor realiza consigo mesmo, atua consigo mesmo [...] qualquer um consegue fazer aquilo, de um modo mais ou menos bom e cada um de uma maneira diferente. A arte mais avançada é a mais democrática, qualquer um pode descrever uma imagem, a descrição produz novas imagem quando se escreve junto o que lhe ocorre durante a descrição. É um modo de encenação disponível a todos que conseguem ver e escrever (MÜLLER 2008: 269-270). ${ }^{16}$

\footnotetext{
${ }^{15}$ Nesse sentido, é interessante a aproximação, proposta por KALB (1998: 170), entre Descrição de imagem e a obra tardia de Samuel Beckett ao comentar o final do texto. Para ele, é a imagem que fala enquanto representação do locutor dividida em muitas identidades animadas e inanimadas. Dada a indeterminação da imagem, cabe ao espectador construí-la mentalmente ao longo da escuta. Uma vez que a construção mental da imagem atemporal ocorre necessariamente no tempo, a mente não pode evitar de parar repetidamente para ponderar a respeito do que é dito.

${ }^{16}$ A relação entre a liberdade do espectador e o feitio democrático da forma foi enfatizado por Müller também no contexto de sua avaliação do teatro de Robert Wilson. Cf. MÜLLER 1986: 153. Cf. também o comentário de BIRKENHAUER (2005b: 105-6): "ao ouvir Descrição de imagem, o ouvinte/espectador repete e produz o processo descrito; ele reconstrói e constrói cenas de uma imagem. Essas cenas
} 


\section{Gatti, L. - Descrição de imagem, H. Müller}

Müller poderia ser criticado por reduzir ao domínio mais íntimo da imaginação individual as pretensões de emancipação coletiva associadas ao modelo da peça de aprendizagem. A descrição, contudo, não aponta para a subjetivação do experimento, mas para a dimensão coletiva da imaginação e da memória. A despeito da eliminação das convenções dramáticas, a concepção de Descrição de imagem como texto para teatro busca associar a posição do espectador à dimensão coletiva da experiência teatral. Pois Müller ainda entendia o drama de maneira coletiva, não mais como imitação de um conflito entre personagens, mas como algo que "surge apenas entre o palco e a plateia e não sobre o palco" (MüLlER 1986: 39). Coletivo, contudo, não implica um efeito de massa. Em uma entrevista de 1981, Müller aponta:

É ali que eu vejo uma possibilidade: utilizar o teatro para grupos bem pequenos (há muito tempo que ele não existe para as massas), de modo a produzir espaços de fantasia, espaços livres para a fantasia - contra esse imperialismo da ocupação da fantasia e da supressão da fantasia por clichês pré-fabricados e pelos padrões da mídia. Penso que essa é uma tarefa política primária, mesmo quando os conteúdos em geral nada tenham a ver com a realidade política (MÜLLER 2005a: 244-5).

Dessa maneira, Descrição de imagem ainda remeteria a uma experiência política entre a cena e espectador. O apreço de Müller por um teatro de paisagens o vincula ao exame de uma história comum, como ele se refere em uma indicação de cena para Margem abandonada medeamaterial paisagem com argonautas (1982) que também valeria para Descrição de imagem: "como em qualquer paisagem, o Eu nesse trecho do texto é coletivo" (MÜLLER 2002: 84). Diante de uma história de catástrofes que paira sobre o presente como a ameaça de uma tempestade apocalíptica, Müller confere ao teatro a tarefa de evocar os mortos e de investigar a paisagem em busca do "erro talvez redentor". É nesse terreno que a "explosão de uma recordação" ainda poderia reverterse em "espaços livres para a fantasia".

permanecem sempre incompletas, desfeitas e destruídas pelo intermitente "ou", pela cena seguinte, antes que possam se estabelecer integralmente. Paradoxalmente é esse processo de progressiva interrupção, que desorganiza e organiza a visão, que constitui a imagem sempre de novo como algo novo a ser visto". 
Gatti, L. - Descrição de imagem, H. Müller

\section{Referências bibliográficas}

BEnJAmin, Walter. "Notizen Svendborg Sommer 1934", in: Gesammelte Schriften VI, Frankfurt am Main, 1991, pp. 525-530. Tradução brasileira em Viso: Cadernos de estética aplicada, v. 9.

BIRKENHAUER, Theresia. Schauplatz der Sprache. Das Theater als Ort der Literaur: Maeterninck, Cechov, Genet, Beckett, Müller. Berlin, Vorwerk 8, $2005 \mathrm{a}$.

BIRKENHAuer, Theresia . "Bild-Beschreibung. Das Auge der Sprache". In Haß, Ulrike. "Jenseits der optischen Höhle. Vom Rythmus des Sehens". In: HAß, Ulrike (Hrsg.). Heiner Müller Bildbeschreibung. Ende der Vorstellung. Berlin, Theater der Zeit, 2005b, pp. 93-111.

BONNAUD, Irène. 'The invention of the body snatchers". In: HAß, Ulrike (Hrsg.). Heiner Müller Bildbeschreibung. Ende der Vorstellung. Berlin, Theater der Zeit, 2005, pp. 135-143.

BRECHT, Bertolt. "Notizen über V-Effekte". In Gesammelte. Werke 15. Frankfurt am Main, Suhrkamp, 1967.

EKE, Norbert Otto. Heiner Müller: Apocalypse und Utopie. Padeborn, Schöning, 1989.

GAGNEBIN, Jeanne Marie. „Críticas estéticas e políticas da kátharsis compreendida como identificação“. In: Rodrigo DUARTE; Virgínia FIGUEIREDO; Verlaine FrEITAS; Imaculada KAngussu. (Org.). Kátharsis. Reflexões de um Conceito Estético. Belo Horizonte: Editora C/Arte, 2002, pp. 153-162.

GATTI, Luciano. „A medida, de Brecht: um exercício de postura“, in: Literatura e Sociedade no. 15. FFLCH-USP, 2011.

HAHN, Barbara. "Alkestis' Wiederkehr. Vom Schreiben in einer 'Traumphase'”. In: HAß, Ulrike (Hrsg.). Heiner Müller Bildbeschreibung. Ende der Vorstellung. Berlin, Theater der Zeit, 2005, pp. 79-92.

HAß, Ulrike. "Jenseits der optischen Höhle. Vom Rythmus des Sehens". In: HAß, Ulrike (Hrsg.). Heiner Müller Bildbeschreibung. Ende der Vorstellung. Berlin, Theater der Zeit, 2005, pp. 199-211.

HEEG, Günther. "Geschlechtermaskerade Fin der partie Mit-Teilung”. In: HAß, Ulrike (Hrsg.). Heiner Müller Bildbeschreibung. Ende der Vorstellung. Berlin, Theater der Zeit, 2005, pp. 158-169.

JOURDHEUIL, Jean. "Surveillance - Beschreibung - Versuchsanordnung". In: HAß, Ulrike (Hrsg.). Heiner Müller Bildbeschreibung. Ende der Vorstellung. Berlin, Theater der Zeit, 2005, pp. 37-49.

KALB, Jonathan. The Theater of Heiner Müller. Cambridge, Cambridge University Press, 1998. KeIM, Kaharina. Theatralität in den späten Dramen Heiner Müllers. Tübingen, Niemayer, 1998.

LEHMANN, Hans-Thies. "Zwischen Monolog und Chor. Zur Heiner Müllers Dramaturgie", in Das Politische Screiben. Berlin, Theater der Zeit, 2002, pp. 338-353.

LeHMANN, Hans-Thies . "Theater der Blicke. Zu Heiner Müllers Bildbeschreibung”, in: HAß, Ulrike (Hrsg.). Heiner Müller Bildbeschreibung. Ende der Vorstellung. Berlin, Theater der Zeit, 2005, pp. 63-78.

LESSING, Gotthold Ephaim. Laocoonte. Sobre as fronteiras entre a poesia e a pintura. São Paulo, Iluminuras, 1998.

LUKÁCS, Georg. "Erzählen oder Beschreiben? Zur Diskussion über den Naturalismus und Formalismus. In: Probleme des Realismus. Berlin, Aufbau Verlag, 1955. pp. 103-145.

MAYeR, Brigitte Maria; Schulte, Christian (Hrsg.). Der Text ist der Cojote: Heiner Müller. Bestandsaufnahme. Frankfurt am Main, Suhrkamp, 2004 


\section{Gatti, L. - Descrição de imagem, H. Müller}

MÜLLER, Heiner. Bildbeschreibung Werke 2. Frankfurt am Main, Suhrkamp, 1999, pp. 112119. Tradução brasileira de Cristine Roehring e Marcos Renaux in MÜLLER, Heiner. Medeamaterial e outros textos. São Paulo, Paz e Terra, 1993, pp. 153-160.

MÜLLER, Heiner. Verkommenes Ufer Medeamaterial Landschaft mit Argonauten. In Werke 5. Frankfurt am Main, Suhrkamp, 2002.

MÜLLER, Heiner "Mich interessiert der Fall Althusser...", in Werke 8. Frankfurt am Main, Suhrkamp, 2005a, pp. 241-6.

MÜLLER, Heiner "Brief an Robert Wilson", in Werke 8. Frankfurt am Main, Suhrkamp, 2005b, pp: 315-8.

MÜLLER, Heiner "Fatzer \pm Keuner", in Werke 8, Frankfurt am Main, Suhrkamp, 2005c, pp. 223-231; Tradução brasileira em KoudELA, Ingrid (org.). O espanto no teatro, São Paulo, Perspectiva, 2003, pp. 49-55).

MÜLLER, Heiner "Verabschiedung des Lehrstücks", in Werke 8. Frankfurt am Main, Suhrkamp, 2005 d, p. 187.

MÜLLER, Heiner Autobiographie. Werke 9. Frankfurt am Main, Suhrkamp, 2008.

MÜLLER, Heiner Gesammelte Irrtümer 1. Frankfurt am Main, Verlag der Autoren, 1986.

MÜLLER, Heiner Gesammelte Irrtümer 2, Frankfurt am Main, Verlag der Autoren, 1990.

MÜLLER, Heiner Gesammelte Irrtümer 3, Frankfurt am Main, Verlag der Autoren, 1994.

SCHNEIDER, Manfred. "Im Namen des Bildes". In: HAß, Ulrike (Hrsg.). Heiner Müller Bildbeschreibung. Ende der Vorstellung. Berlin, Theater der Zeit, 2005.

SCHÜTTE, Uwe. Arbeit an der Differenz. Zum Eigensinn der Prosa von Heiner Müller. Heidelberg, Winter, 2010.

recebido em 03/02/2013

aceito em 23/03/2013 